\title{
Behaviour of ${ }^{238} \mathrm{U}$ family radionuclides in continental environment: Case of the $U$ mining area near Limoges (France)
}

\author{
C. Cazala ${ }^{1,2}$ and J .-L. Reyss ${ }^{1}$ \\ ${ }^{1}$ Laboratoire des Sciences du Climat et de l'Environnement, Domaine du CNRS, Av. de la \\ Terrasse, 91198 Gif-sur-Yvette, France \\ ${ }^{2}$ Present address: IRSN/DEI/SARG/LERAR, BP. 17, 92262 Fontenay-aux-Roses, France
}

\begin{abstract}
The objectives of this work are to study the behaviour of ${ }^{238} \mathrm{U}$ and its daughters in the continental environment and to determine the radiological impact of $U$ mining past activities in the Haute-Vienne French administrative division. The distribution of radionuclides among different size fractions was investigated upstream and downstream mines. Particulate $(>0.45 \mu \mathrm{m})$ and dissolved $(<0.45 \mu \mathrm{m})$ fractions were separated by filtration and analysed by gamma spectrometry. A preconcentration step by evaporation was elaborated and validated for liquid samples. Results indicate that radiological impacts of $U$ mines are the enhancement of radionuclides activities and a change of their distribution between particulate and dissolved fractions at $0.45 \mu \mathrm{m}$. While activity levels depend on the input intensity, the distribution is controlled by the mine water treatment witch reduces drastically the contribution of mine radionuclides in streams. Analysis of particles from traps and sediments confirms that the distribution of mine radionuclides promote their accumulation in lacustrian sediments. Nevertheless, the impact of the past activities is very limited in space. Indeed, it becomes weak at $10 \mathrm{~km}$ downstream the inputs and is no more detectable at $30 \mathrm{~km}$ downstream.
\end{abstract}

\section{INTRODUCTION}

Industrial activities, including mining activities, generate chemical and physical changes in their nearby environment. Compared to classic metal extraction industries, uranium mining presents a specificity due to the radiological impact. In France, uranium was extracted from 186 sites until 2001. The Haute-Vienne area (Limoges) was the main place of extraction and has been selected for this study. The aims of this work are to study the behaviour of radionuclides from mines in the environment and to determine the radiological impact of past uranium mining activities on the environment. The distribution of radionuclides among particulate $(>0.45 \mu \mathrm{m})$ and dissolved $(<0.45 \mu \mathrm{m})$ fractions was investigated upstream and downstream mines to better understand the transport of radionuclides in the Vienne river basin.

\section{METHODS}

\subsection{Sites}

Uranium mining started in the Limoges area in 1948 and stopped in 1995. Restoration works were (and are still) conducted to physically, chemically and radiologically secure the former uranium mine sites. Mine water are collected and - if contaminated - chemically treated to reduce their radionuclide content. They are then conveyed to the surface hydrologic web. That is the case for water considered in the present study. 
The investigation was undertaken on two different scales. Changes in surface-water radiological contents due to mine water inputs were mainly studied at a local scale. These effects were also studied, albeit less intensively, at the scale of the River Vienne basin, using several water courses.

At a local scale, the hydrological unit selected consisted of two lakes connected by a small stream; the latter of which collects mine waters (Figure 1). The Lake "Gouillet" (point A), situated upstream of former mines, was sampled to determine background, outside the influence of the mines. Three other sites were located inside the mine water affected zone. The first corresponds to the small (flow rate : $0.4 \mathrm{~m}^{3} \cdot \mathrm{s}^{-1}$ ) River "Ritord" (point B) whereas the second was in the Lake "Saint-Pardoux" (point C) created in 1976 by the building of a dam. The third site was sited immediately below the dam (point D).

At a large scale some other streams were studied to determine the global impact of the former mining activities. All of these streams join the River "Gartempe" before it joins the Rivers "Creuse" and finally the "Vienne" (Figure 1).

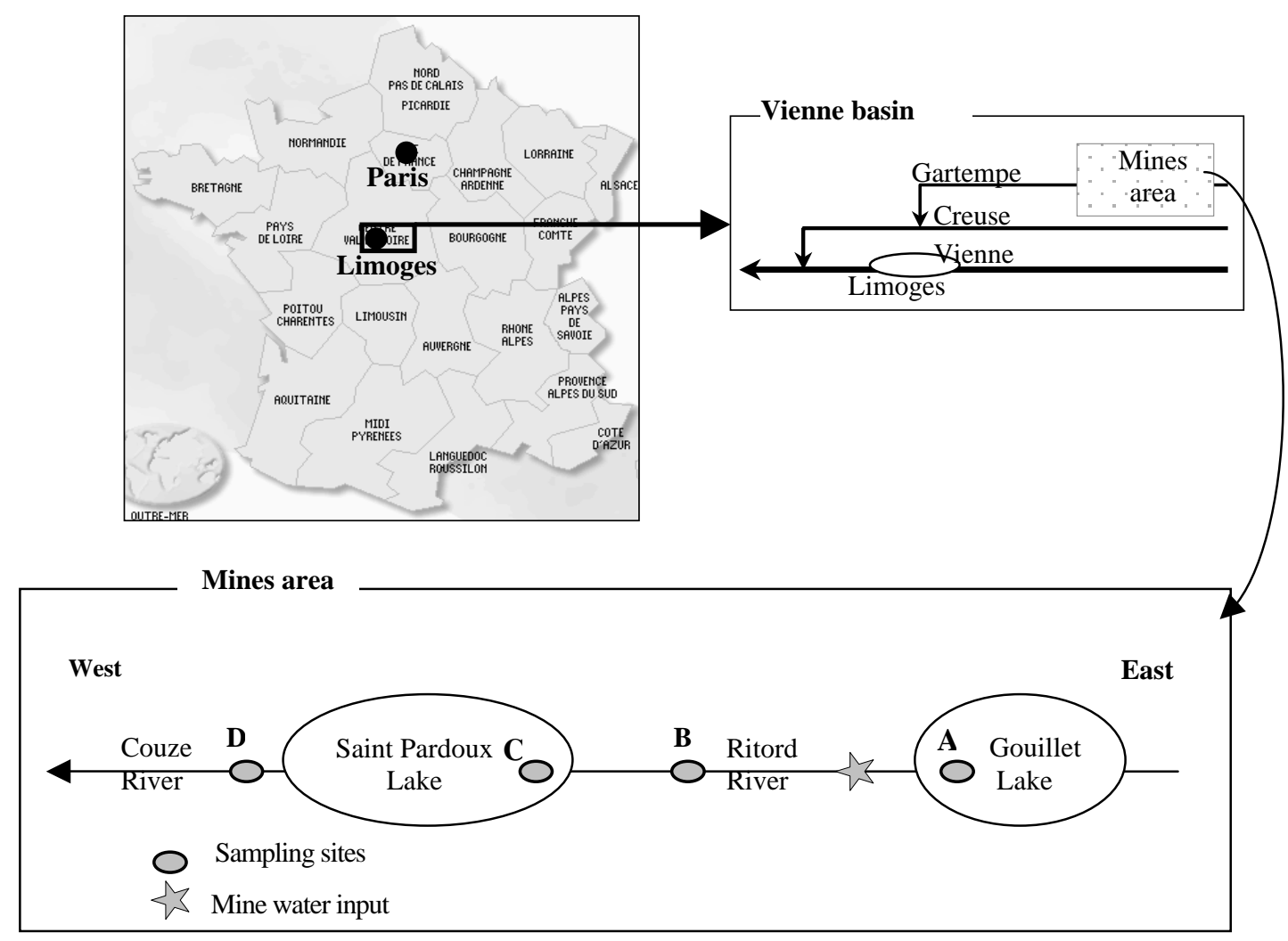

Figure 1. Location of the study area and the sampling sites within it.

\subsection{Samples collection and treatment}

Unfiltered water, particles removed by filtration at $0.45 \mu \mathrm{m}$ and dissolved fraction were analysed by gamma spectrometry to measure simultaneously ${ }^{238} \mathrm{U},{ }^{234} \mathrm{Th},{ }^{226} \mathrm{Ra},{ }^{210} \mathrm{~Pb},{ }^{228} \mathrm{Ra},{ }^{228} \mathrm{Th},{ }^{7} \mathrm{Be},{ }^{137} \mathrm{Cs}$ and ${ }^{40} \mathrm{~K}$ activities. Liquid samples were evaporated in the presence of carriers before measurement [1-2]. The residue of evaporated water samples were crushed. Particles removed by filtration were dried at $70^{\circ} \mathrm{C}$. Then each sample was sealed in a polypropylene tube for gamma spectrometry. 
High efficiency, very low background, well-type Ge of $430 \mathrm{~cm}^{3}$ and $930 \mathrm{~cm}^{3}$ detectors [EURISYS MESURE (presently Canberra-Eurisys) [3], were used for the measurements. Six standards were used to calibrate the gamma detectors which are implanted in the Underground Laboratory of Modane (LSM). This laboratory, jointly operated by the Centre National de la Recherche Scientifique (CNRS) and the Commissariat à l'Energie Atomique (CEA), is located in the Alps at the mid-point of the Frejus road tunnel, close to the Italian-French border. The laboratory is overlain by $1700 \mathrm{~m}$ of rock, which reduces the cosmic ray muon fluence rate to $4 \mathrm{~m}^{-2} \mathrm{~d}^{-1}$. The ventilation system, which renews the air twice per hour in the gamma spectrometry room, keeps the radioactivity of radon and its daughter products down to 5-15 $\mathrm{Bqm}^{-3}$. The integrated background counting rate from 30 to $3,000 \mathrm{keV}$ is as low as 792 counts per day for the $930 \mathrm{~cm}^{3}$ detector and 850 for the $430 \mathrm{~cm}^{3}$ detector, which is about three orders of magnitude lower than at ground level. Generally, one day of counting of the residues from 3 litres of evaporated water leads to a statistical counting uncertainty less than $10 \%$ for most of the radionuclides of interest [1].

\section{RESULTS AND DISCUSSION}

\subsection{Local scale}

The figure 2, presents mean ${ }^{238} \mathrm{U},{ }^{226} \mathrm{Ra}$ and ${ }^{210} \mathrm{~Pb}$ activities determined from the Lake "Gouillet" to the point C located downstream the Lake "Saint Pardoux". Samples were regularly collected from January 2001 to October 2002. ${ }^{238} \mathrm{U},{ }^{226} \mathrm{Ra}$ contents of water in the Lake "Gouillet" (point A) are close to $10 \mathrm{mBq} \cdot \mathrm{l}^{-1}$ whereas ${ }^{210} \mathrm{~Pb}$ reaches $30 \mathrm{mBq} \cdot \mathrm{l}^{-1}$. The excess of ${ }^{210} \mathrm{~Pb}$ could partly be explained by atmospheric deposition using 7Be as tracer of the atmospheric radionuclides input.

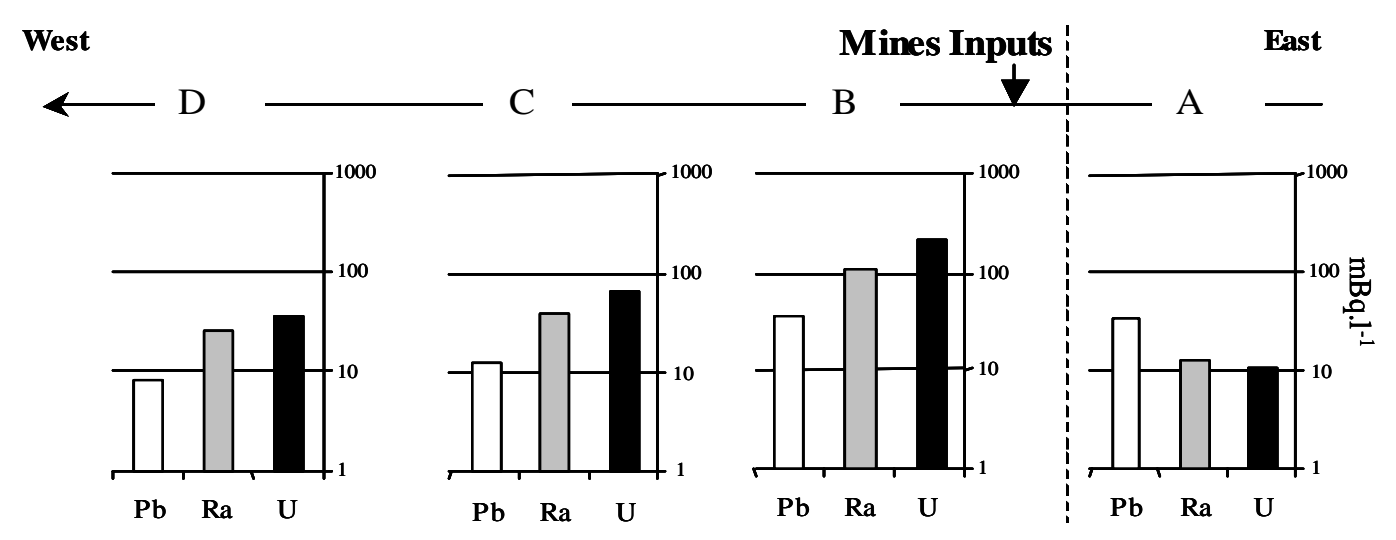

Figure 2. ${ }^{238} \mathrm{U},{ }^{226} \mathrm{Ra}$ and ${ }^{210} \mathrm{~Pb}$ mean activities upstream (point A) and downstream (points $\mathrm{B}$ to $\mathrm{D}$ ) of the inputs of mine waters.

${ }^{238} \mathrm{U},{ }^{226} \mathrm{Ra}$ activities increase downstream of the mine and then decrease with increasing distance from the mine water inflow point. Compared to ${ }^{238} \mathrm{U}$ and ${ }^{226} \mathrm{Ra},{ }^{210} \mathrm{~Pb}$ presents a singularity as its activity do not increase significantly downstream the mine. Sites located inside the area under the influence of the mines (B to D) are characterized by ${ }^{238} \mathrm{U}$ and ${ }^{226} \mathrm{Ra}$ activities higher than those encountered at the reference site (A) whereas ${ }^{210} \mathrm{~Pb}$ activity is not drastically impacted by mine water inflow. As the mine water corresponds to the main water inflow to the stream between A and B it can be considered that the difference of radiological composition of water between those two points can be attributed to the mine water inputs. Therefore, it can be deduced that mine waters are characterized by a high ${ }^{238} \mathrm{U}$ and ${ }^{226} \mathrm{Ra}$ activity whereas ${ }^{210} \mathrm{~Pb}$ activity is in the same order of magnitude than at the reference point $\mathrm{A}$. 
As mentioned above, ${ }^{238} \mathrm{U},{ }^{226} \mathrm{Ra}$ and ${ }^{210} \mathrm{~Pb}$ activities diminish through the lake. Two hypotheses can be advanced to account for this: i) dilution; and ii) sedimentation. As the River Ritord constitute the main source of water in the part of the lake where the sampling point "C" is situated, the hypothesis of sedimentation is promoted.

This can be tested by studying the distribution of radionuclides between particulate (larger than $0.45 \mu \mathrm{m}$ ) and dissolved (less than $0.45 \mu \mathrm{m}$ ) fractions. The mean distribution of ${ }^{238} \mathrm{U},{ }^{226} \mathrm{Ra}$ and ${ }^{210} \mathrm{~Pb}$ determined between January 2001 and October 2002 are presented in figure 3.

The distribution of radionuclides between particulate and dissolved fractions most likely controls their transportation in the watershed. Thirty percent of the ${ }^{238} \mathrm{U},{ }^{226} \mathrm{Ra}$ and ${ }^{210} \mathrm{~Pb}$ activity is associated with particles in the Lake "Gouillet" (point A) considered as an undisturbed site. From the increase of activities between points A and B (River Ritord), it is estimated that more than $80 \%$ of the activity measured at the latter site comes from mine waters. Therefore, the radionuclide distribution observed at this location should be most similar to that of the treated mine waters. For uranium and lead, the percentage of activity associated with particles reached $50 \%$ and $70 \%$ respectively at the River Ritord (point B). The previous conclusion that radionuclide exportation in the lake occurs by sedimentation is supported by the simultaneous diminution of ${ }^{238} \mathrm{U},{ }^{226} \mathrm{Ra}$ and ${ }^{210} \mathrm{~Pb}$ activity percentages associated with particles. Chemical treatment of mine waters enhance the retention of radionuclides in the watershed.

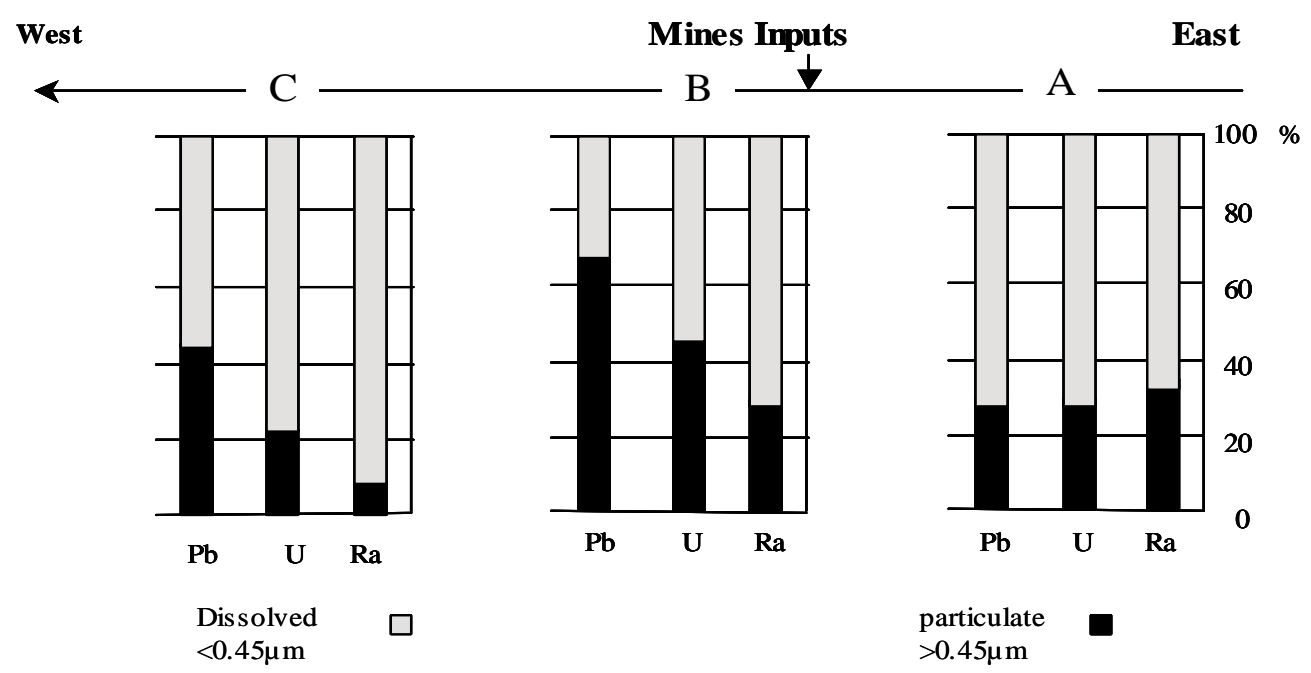

Figure 3. Mean distribution of ${ }^{238} \mathrm{U},{ }^{226} \mathrm{Ra}$ and ${ }^{210} \mathrm{~Pb}$ between particulate $(>0.45 \mu \mathrm{m})$ and dissolved $(<0.45 \mu \mathrm{m})$ fractions.

\subsection{Regional scale}

${ }^{238} \mathrm{U},{ }^{226} \mathrm{Ra}$ and ${ }^{210} \mathrm{~Pb}$ activities determined in the River Vienne watershed are presented on the Figure 4. Reported values corresponding to the hydrological unite composed of the Lake Gouillet, the River Ritord and the Lake Saint-Pardoux and the River Couze (A to D) are mean values of activities determined between January 2001 and October 2002. The "Sauvage" reservoir is the upper sampled site in the watershed. This lake is fed both by rain, and water from peat. ${ }^{238} \mathrm{U}$ and ${ }^{226} \mathrm{Ra}$ activity levels are low (both $3 \mathrm{mBqL}^{-1}$ ). In contrast, the ${ }^{210} \mathrm{~Pb}$ activity was close to those encountered downstream of the $\mathrm{U}$ mines. ${ }^{238} \mathrm{U}$ and ${ }^{226} \mathrm{Ra}$ activities of lower sites in the basin but still upstream of the mines (Lake Gouillet and its tributaries Dauges stream, and the Rivers Gartempe and Vienne), were significantly higher than in Lake Sauvage. This could be due to weathering of granite. 
The increase in ${ }^{238} \mathrm{U}$ and ${ }^{226} \mathrm{Ra}$ activity of mine-affected the River Ritord waters also occurrs in waters sampled below other U mines (symbolised on Figure 4 by stars). The River Ritord U mine waters are chemically treated. This is not the case for the stream Sagnes which cross mines. The "South" tributary of Lake Crouzille should not be influenced by mine waters due to restoration works (conducted on the Henriette mine located near the stream) which are intended to direct waters to another brook via a chemical treatment station. The activities encountered in the stream "South" nevertheless indicate that there were losses during water collection and/or progress to the station. This could possibly be improved by increasing soil density in areas of recent restoration works, and by checking for leaks in pipes.

It would be useful to compare radiological activities determined for the streams Ritord, Sagnes and South, but this is not possible because our reported values for the River Ritord are mean values, whereas those for the two other streams (Sagnes and South) come from single samples. Nevertheless, when water was not treated and the mine not rehabilitated (Sagnes case), activities appeared to reach levels far higher than those observed for the River Ritord during this study. This supports the view that restoration works and/or chemical treatment are efficient means of contamination reduction. Study of sediments from Lake Crouzille indicates that radionuclide sequestration occurs in the same way as in the Lake St-Pardoux (unpublished results). Rivers exiting these two reservoirs under the influence of mines join the River Gartempe, where radiolological activities compare with those determined upstream of the mines. Consequently, the radiological impact of former uranium mining activities exists but it is very limited in space on a regional scale. Restoration works and chemical treatments diminish the radiological activities, but it is important that lake sediments appear to naturally attenuate radionuclide contamination that is associated with particles.

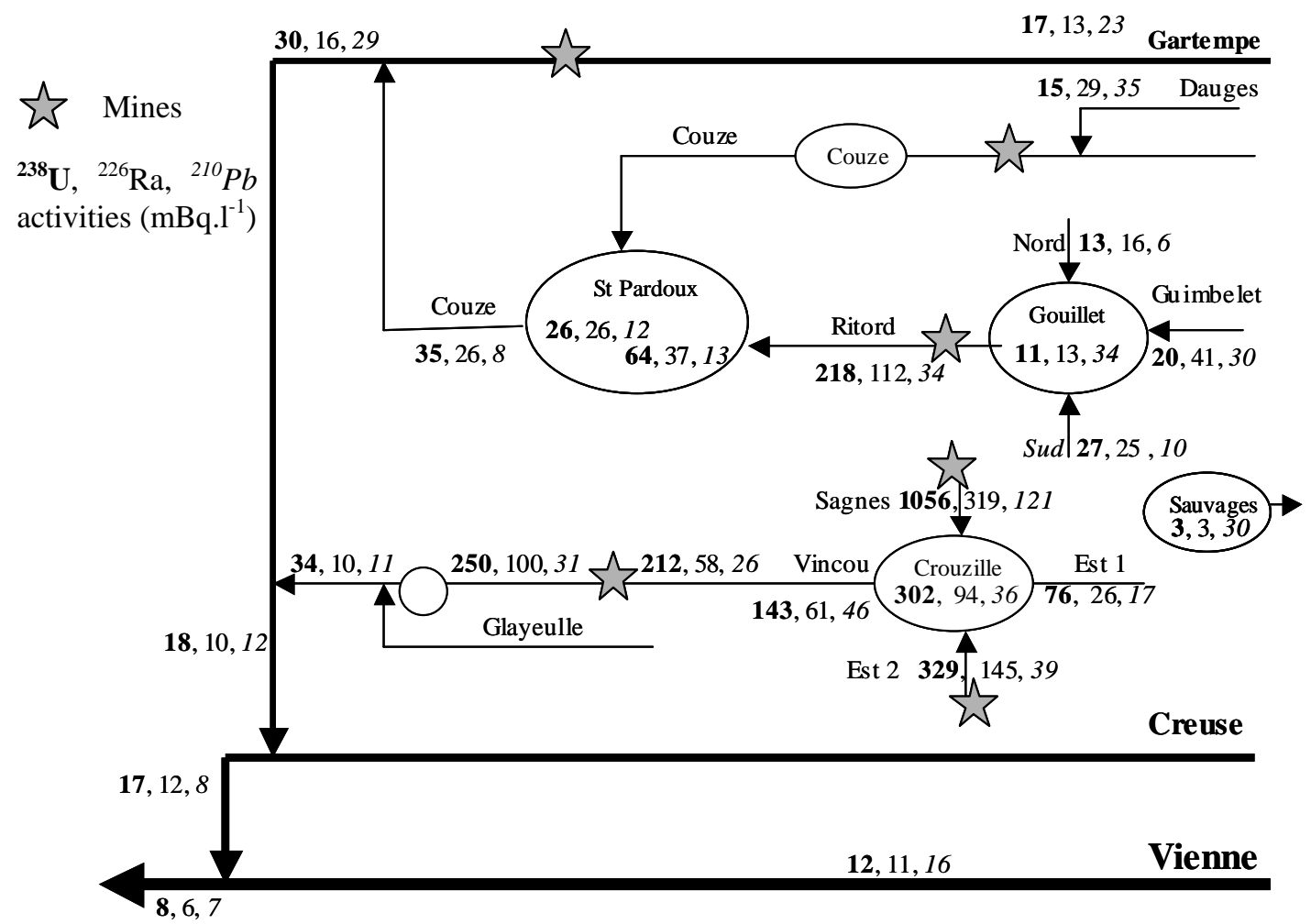

Figure 4. ${ }^{238} \mathrm{U},{ }^{226} \mathrm{Ra}$ and ${ }^{210} \mathrm{~Pb}$ activities determined on the Vienne River watershed. 


\section{Acknowledgements}

The authors are grateful to the Conseil general de le Haute Vienne for supporting this work. The CEMRAD (University of Limoges) gave considerable support for this study and we acknowledge J.L. decossa and A. Royer for their help.

\section{References}

[1] Cazala C., Reyss J-L, Decossa J-L and Royer A..Environ. Sci. Technol. 37 (2003) . 4990-4993.

[2] Cazala C. Thèse. Univ Paris 6 (2003) 210pp.

[3] Reyss J.L., Schmidt S., Legeleux F., Bonte P. Instr. Meth., A 357 (1995) 391-397. 